\title{
KETAMINE AS A POTENTIAL THERAPEUTIC AGENT IN OBSESSIVE-COMPULSIVE DISORDER
}

\author{
C. Fernandes Santos, N. Descalço, F. Fernandes Martins
}

Department of Psychiatry and Mental Health, Hospital Garcia de Orta - Almada, Portugal

\section{OBJECTIVES}

To review the clinical evidence for therapeutic utility of ketamine as an augmentation or monotherapy in patients with obsessive-compulsive disorder (OCD).

\section{BACKGROUND}

OCD is a clinically heterogeneous neuropsychiatric disease, affecting $1-3 \%$ of the population and being a leading cause of illness-related disability ${ }^{1,2,3}$.

It can be treated using pharmacotherapy, specialized psychotherapy, anatomically targeted treatments, or their combination ${ }^{4}$.

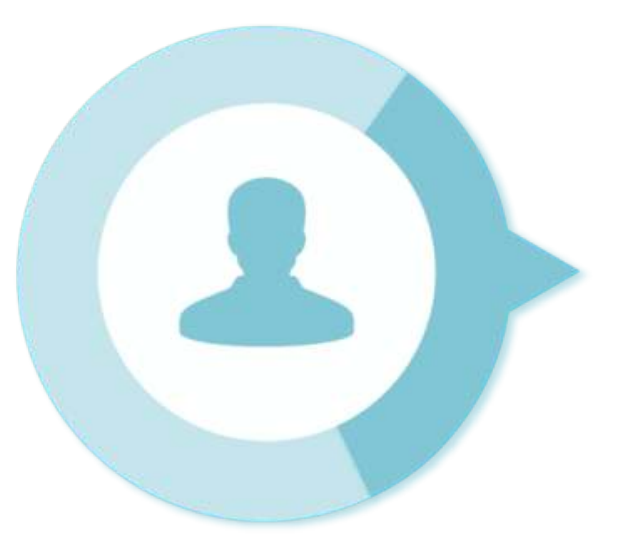

One-third of patients with OCD fail to experience significant clinical benefit from first-line interventions - cognitive behavioral therapy (CBT) and pharmacotherapy with the selective serotonin reuptake inhibitors (SSRIs) $)^{1,5,6}$.

Unfortunately, even with optimal treatment, many patients continue to experience significant symptoms. Remission of moderate or severe OCD is uncommon, and long-term management is often necessary. The development of new, more effective treatment interventions represents an urgent clinical need ${ }^{1,4,5,7,8,9}$.

Converging lines of evidence from brain-imaging, genetic, and pharmacological studies implicate a fundamental dysregulation of glutamate homeostasis in the pathogenesis of OCD $\mathbf{D}^{1,2,4,6,7,8,9}$.

Glutamate-modulating agents, such as ketamine, have been shown to improve OCD symptoms ${ }^{10,11}$ and this work aims to review its therapeutic utility.

\section{MATERIALS AND METHODS}

Non-systematic review of literature published in 2010-2019, on PubMed/MEDLINE, corresponding to 'obsessive-compulsive disorder' and 'ketamine'.

\section{RESULTS}

Glutamate is the primary neurotransmitter within the corticostriatal-thalamic circuits, implicated in $\mathbf{O C D} \mathbf{D}^{2,8,11}$.
Ketamine is a potent noncompetitive antagonist of the $\mathbf{N}$ methyl-D-aspartate (NMDA) glutamate receptor and its neuropsychiatric interest derives from effects at subanesthetic doses $(0.5 \mathrm{mg} / \mathrm{kg} \text { infused over } 40 \text { minutes })^{1,2,3,6,7,8,11}$.

\section{EFFICACY}

- The results from trials on intravenous ketamine efficacy in OCD are contradictory ${ }^{6,8}$ :

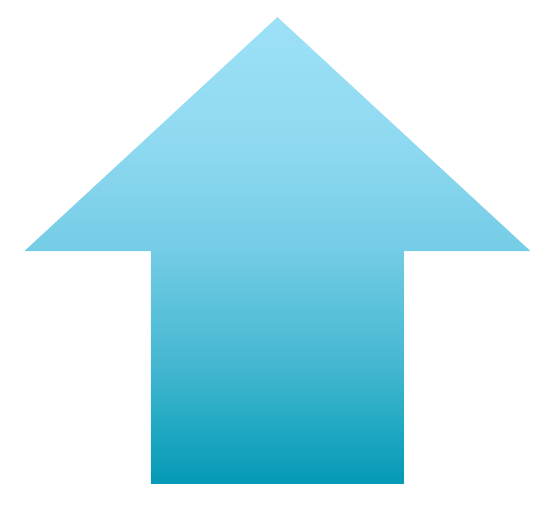

Rapid decrease in symptomatology (50\% met criteria for treatment response: $\geq 35 \%$ decrease in the Yale-Brown Obsessive Compulsive Scale $[\mathrm{Y}-\mathrm{BOCS}]^{8}$ ).

Sustainability of its effect over a clinically meaningful period of time differed greatly - from 1-3 days to one week after infusion.

- Individuals with constant intrusive obsessions may represent an OCD subtype more sensitive to ketamine's effects $^{8}$;

- OCD patients with comorbid depression may represent a subtype of illness that is ironically less responsive to ketamine effects on OCD symptoms ${ }^{8}$.

\section{SIDE EFFECTS $3,6,8$}

- During infusion: mild elevations in blood pressure and pulse; dissociation (feelings of unreality, distortions of time level of dissociation may influence ketamine's effects in OCD), psychotic symptoms (unusual thought content, conceptual disorganization, manic symptoms (elevated mood);

- Post-infusion: dizziness, nausea, vomiting, headache.

\section{CONCLUSIONS}

Ketamine can have rapid anti-obsessional effects that persist for one week in some patients with OCD $2,3,4,6,8$.

Future research is needed to clarify the mechanism of ketamine's acute effects and why some - but not all - patients benefit. Ketamine may provide a useful tool to study the glutamatergic mechanism implicated in OCD and, if proven effective, may help identify novel drug targets.

REFERENCES: 1. Tosta CL, et al. S-ketamine reduces marble burying behaviour: Involvement of ventromedial orbitofrontal cortex and AMPA receptors. Neuropharmacology. 2019 Jan;144:233243. Epub 2018 Oct 29. 2. Marinova Z, Chuang DM, Fineberg N. Glutamate-Modulating Drugs as a Potential Therapeutic Strategy in Obsessive-Compulsive Disorder. Curr Neuropharmacol. 2017;15(7):977-995. 3. Rodriguez Cl, et al. Rapid resolution of obsessions after an infusion of intravenous ketamine in a patient with treatment-resistant obsessive-compulsive disorder. J Clin Psychiatry. 2011 Apr;72(4):567-9. 4. Pittenger C, Bloch MH. Pharmacological Treatment of Obsessive-Compulsive Disorder. Psychiatr Clin N Am. 2014;37:375-391. 5. M Koran L, Aboujaoude E. Promising Treatments for Obsessive-Compulsive Disorder: A Call for Additional Research. Curr Med Chem. 2018;25(41):5690-5697. 6. Bloch MH, et al. Effects of ketamine in treatment-refractory obsessive-compulsive disorder. Biol Psychiatry. 2012 Dec 1;72(11):964-70. 7. Rodriguez Cl, et al. In vivo effects of ketamine on glutamate-glutamine and gamma-aminobutyric acid in obsessivecompulsive disorder: Proof of concept. Psychiatry Res. 2015 Aug 30;233(2):141-7. 8. Rodriguez Cl, et al. Randomized controlled crossover trial of ketamine in obsessive-compulsive disorder: proof-of-concept. Neuropsychopharmacology. 2013 Nov;38(12):2475-83. 9. Pittenger C. Glutamatergic agents for OCD and related disorders. Curr Treat Options Psychiatry. 2015 Sep;2(3):271283. 10. Rodrigu ez Cl, et al. Challenges in Testing Intranasal Ketamine in Obsessive-Compulsive Disorder. J Clin Psychiatry. 2017 Apr;78(4):466-467. 11. Pittenger C. Glutamate modulators in the treatment of obsessive-compulsive disorder. Psychiatr Ann. 2015 Jun;45(6):308-315.

catiafersantos@gmail.com 